\title{
A Prospective Study of Clinical, Epidemiological and Serologic Status Features in a Paediatric Pcr Sars-Cov-2 Positive Population
}

\author{
Ignacio Callejas Caballero \\ Hospital Universitario de Getafe \\ Alba Ruedas López \\ Hospital Universitario Clínico San Carlos \\ Arantxa Berzosa Sánchez \\ Hospital Universitario Clínico San Carlos \\ Marta Illán Ramos \\ Hospital Universitario Clínico San Carlos \\ Belén Joyanes Abancens \\ Hospital Universitario Clínico San Carlos \\ Andrés Bodas Pinedo ( $\square$ abodas@pdi.ucm.es ) \\ Hospital Universitario Clínico San Carlos \\ Sara Guillén Martín \\ Hospital Universitario de Getafe \\ Beatriz Soto Sánchez \\ Hospital Universitario de Getafe \\ Isabel García Bermejo \\ Hospital Universitario de Getafe \\ David Molina Arana \\ Hospital Universitario de Getafe \\ Juan-Ignacio Alós \\ Hospital Universitario de Getafe \\ Elvira Baos Muñoz \\ Hospital Universitario Clínico San Carlos \\ Alberto Delgado Iribarren \\ Hospital Universitario Clínico San Carlos \\ Manuel Enrique Fuentes Ferrer \\ Hospital Universitario Clínico San Carlos \\ José Tomás Ramos Amador \\ Hospital Universitario Clínico San Carlos
}

Research Article

Keywords: RT-PCR (reverse transcriptase polymerase chain reaction), SARS-CoV2, COVID-19, seroconversion, children

Posted Date: January 3rd, 2022

DOI: https://doi.org/10.21203/rs.3.rs-1204817/v1

License: (c) (7) This work is licensed under a Creative Commons Attribution 4.0 International License. Read Full License 


\section{Abstract}

\section{Background:}

Although most cases of SARS-CoV-2 infection in pediatric population are asymptomatic or mild, severe cases may occur in a small percentage. Unlike other respiratory infections, children usually develop it from infected adults. Percentage of seroconversión and outcome of antibodies after infection anti-SAR-CoV-2 in children are still poorly understood and may be different from adults. The first aim was to describe clinical and epidemiological characteristics of pediatric patients diagnosed of SARS-CoV-2 infection in the second epidemic wave in two tertiary hospitals in Madrid, Spain and to determine the proportion of seronegative by comparing 3 serological techniques. As secondary aim it was proposed to determine the proportion of seronegative by comparing 3 serological techniques, seroconversion associated variables and the way of infection among the family members.

\section{Methods:}

Multicenter prospective observational study in two university hospitals of the Community of Madrid, between September and November 2020, of COVID-19 infection confirmed by PCR in the Emergency Department.

A retrospective data collection was performed at 4-8 weeks after diagnosis on an outpatient basis, using a clinical-epidemiological questionnaire. At this time blood samples were collected to analyse the humoral response by 3 different serological assays.

The quantitative variables are expressed as medians (interquartile range (IQR) 25-75).

Univariate analysis of possible factors associated with seropositivity absence was performed.

\section{Results:}

One hundred and eleven patients (58 girls) were included with a median days of 37 (IQR: 34-44) between diagnosis and serologic test performed.

Median age was 88 (IQR: 24-149) months. Parents were from abroad in 62 cases (50\% from South and Central America).

Ninety eight children were symptomatic, 17 children were diagnosed by epidemiological screening, 4 of whom subsequently developed symptoms.

Eight of them needing admission with a median length of stay 2 days (IQR: 2-4), none of them in PICU.

Underlying conditions were found in 33 patients, mainly recurrent bronchitis.

Most frequent symptoms $(70 \%)$ were low-grade fever $\left(37-38^{\circ} \mathrm{C}\right)$ or fever $\left(\geq 38^{\circ} \mathrm{C}\right)$, rhinorrhea $44 \%$, cough $31.5 \%$, headache $29.7 \%$, weakness $27 \%$, diarrhea $19.8 \%$, abdominal pain and vomiting $26 \%$, anosmia $16.2 \%$ (median 10 days; IQR: 6-30). Infection was interpreted as a secondary case in 56 patients, being a relative the index case in $96.4 \%$.

Seronegativity was observed in 19 patients in any of the 3 serological techniques (17.1\%; $95 \% \mathrm{Cl}$ : 10.6-25.4), this proportion was higher among children aged 2-to 10 -year-old age $(16$ of $45 ; 35 \%, p<0.05)$.

In univariate analysis a lower proportion of seroconversion was found in those children in whom COVID-19 confirmation is not documented among household contacts $(15 / 29 ; 51.7 \%$; $p<0.05)$.

\section{Conclusions:}

Our results confirm the mild clinical picture in children during the second epidemic wave, and that in most cases, children are not the index case in the family. Likewise, in children the proportion in whom seroconversion is not detected is high, and seems higher than that reported in adults. In our series, an association of seronegativity was seen in the 2 to 10 year-old age group and when there was no documentation of COVID-19 in any household contact.

\section{Background}


The disease caused by SARS-CoV-2 (severe acute respiratory syndrome coronavirus 2) was declared a global pandemic by OMS in March 2020 and it was designed as COVID-19. From the initial description it was patent the less severe disease in pediatric population ${ }^{1-3}$. However a small proportion of children might develop a severe clinical course ${ }^{4}$ or present as multisystem inflammatory syndrom related to SARS-CoV-2 (MIS-C) ${ }^{5}$. Although some studies show that the risk of infection in children is similar to adults ${ }^{6}$, others indicate that children may be less prone to infection $4,7,8$ and that the prevalence is lower at early ages ${ }^{9}$.

In adult population it has been shown that the proportion of non-seroconverters is higher in paucisymptomatic patients or in the less severe cases ${ }^{10-12}$, being the most ill patients the ones with higher titers of antibodies ${ }^{13}$. Children tend to develop mild or even asymptomatic disease more often than adults ${ }^{14-15}$. This could lead to the possibility that the proportion of patients in whom no antibodies are detected is higher in the pediatric population as compared to adults ${ }^{16,17,18}$.

There is evidence that the level of antibodies against the receptor - binding domain (RBD) of SARS-CoV-2's Spike protein correlates with neutralizing antibodies which are of major importance in the protection against future infections. Nevertheless, kinetics of these two types of antibodies might not be the same ${ }^{19}$. Little is known about the evolution of antibodies against different antigens of SARS-CoV-2 in children, being the information yet scarce ${ }^{20}$. There is a decrease of the level of IgG antibodies after 6 months of infection in both children and adults ${ }^{20}$. Titers of neutralizing antibodies may stay high for longer periods of time specially in children aged 3 or less, even with higher levels found than in older children or adults ${ }^{20}$. The knowledge of the kinetics of the several antibodies produced after COVID-19 in children and its outcome could be of great importance in the protection against new infections and the response to vaccines.

The main aim of this study were to describe the clinical manifestations and epidemiological characteristics of SARS-CoV-2 in a pediatric population attended in two universitary hospitals in Madrid during the second wave of the pandemic in Spain and to analyse the proportion of seronegative patients at $4-8$ weeks by 3 different serologic techniques. Other aims were the análisis of possible factors related to non-seroconversion, determine the concordance between the three serological techniques and the way of infection among the family members.

\section{Methods \\ Study design:}

Multicenter prospective observational study includin children and adolescents who were attended at two universitary hospitals in Madrid (Hospital Clinico San Carlos and Hospital de Getafe) between September and November 2020, period corresponding to the second wave of the pandemic in Spain.

\section{Study population:}

All children and adolescents between 0 and 18 who were attended in the emergency room with SARS-CoV-2 infection confirmed were included.

Confirmed infection was considered when reverse transcription-polymerase chain reaction (RT-PCR) in a sample obtained from nasopharyngeal swab turned postive.

In the second wave, in order to increase detection of SARS-CoV-2 and to improve tracking contacts, a whole RT-PCR test was carried out by protocol in the Pediatric Emergency Department of both hospitals to all children who were attended for compatible symptoms. These included fever, respiratory, digestive or skin symptoms, as well as a history of recent close contact with a patient diagnosed with COVID$19^{21}$.

Those with confirmed infection were referred as outpatients to the clinic at 4-8 weeks,

and were offered to participate in the present study, requiring to complete a clinical-epidemiological questionnaire and a blood sample, drawn for serology.

Exclusion criteria were: immunosuppressed patients, rejecting to sign an informed consent, extraction of blood sample for serology outside the period of 4-8 weeks after a positive RT-PCR result, and not having available all 3 serological techniques results due to insufficient serum sample.

\section{Data collection and study variables:}


The following variables were collected: demographic characteristics (age, sex, date of birth, place of birth, parental origin), relevant personal history, clinical manifestations at the time of going to the emergency room according to the corresponding medical report, as well as information collected in questionnaire at the first consultation visit 4-8 weeks after diagnosis. The following clinical manifestations were collected: fever $\left(\geq 38^{\circ} \mathrm{C}\right)$, cough, dyspnea, gastrointestinal symptoms (abdominal pain, nausea, vomiting and / or diarrhea), skin lesions, neurological symptoms and other features.

Data related to diagnosis, treatment/procedures and outcome were also collected, both int he time of diagnosis and the follow-up.

A seropositive patient was defined as the presence of humoral response in at least one of the 3 serological techniques and a seronegative patient if no humoral response was obtained in any of the 3 serological techniques.

The questionnaire also included questions about whether a family member or the child were the first with appearing symptoms, so to define the index case. The index case was defined as the subject with a confirmatory RT-PCR for SARS-CoV-2 infection and with an earlier onset date of symptoms in a specific setting. Cases with symptoms onset shorter than 24 hours from the start date of the index case were considered co-primary cases. The subject in contact with an index case with a positive diagnostic test 24 hours or more after the date of the last positive test of the primary or co-primary case was defined as a secondary case. When symptoms appeared 24 hours or more after the date of symptoms initiation of the primary or co-primary case was also defined as a secondary case ${ }^{22}$.

The study was approved by the Ethics Committees of the two participating hospitals.

\section{Informed consent}

signed by parents or guardians was required in all patients as well as informed assent in the mature minor (over 12 years old) following current regulations (Declaration of Helsinki, Law 14/2007 of July 3 on Biomedical Research).

\section{Microbiological tests:}

RT-PCR of nasopharyngeal swab was used for detection of SARS-CoV-2. Detection of serum antibodies against SARS-CoV-2 was carried out according to the manufacturer's instructions performing 3 serological tests: Siemens (ADVIA Centaur ® XP SARS-CoV-2 Total (COV2T)); Abbott (Alinity ${ }^{\circledR}$ SARS-CoV-2 IgG II) and anti-IgG/A/M SARS-CoV-2 ELISA test (Human IgG/IgA/IgM anti-SARS-CoV-2 ELISA by The Binding Site Group Ltd., Birmingham, UK). The COV2T test (Siemens) is a chemiluminescent immunoassay (CLIA) for the qualitative detection of IgG and IgM antibodies against the spike protein (IgG-S and IgM-S) of SARS-CoV-2 in serum and plasma. This test uses a recombinant receptor-binding domain (RBD) antigen contained in the S1 subunit of the SARS-CoV-2 spike protein (S). Results are considered positive if index is $\geq 1$ and negative if $<1$. The index value is established by two calibrators and ranges from 0.05 to 10.00 . Abbott SARS-CoV-2 IgG II assay is a chemiluminescent microparticle immunoassay (CMIA). This test performs a qualitative determination of IgG antibodies against nucleocapsid protein (N) of SARS-CoV-2 (IgG-N) in serum and plasma. A result $\geq 1.4$ is considered positive and negative when the index is $<1.4$. The anti-SARS-CoV-2 IgG / IgA / IgM assay is based on the determination of anti-RBD $\lg / \lg A / \lg M$ antibody titers using the ELISA technique (enzyme-linked immunosorbent assay or immunosorbent assay linked to enzymes). Antibody titers are estimated by generating isotype-specific standard curves using monoclonal anti-SARS-CoV-2 IgG, IgA and / or IgM antibodies. Following the manufacturer's instructions positive samples were identified as those with a UR / $\mathrm{mL}$ three standard deviations above negative control samples mean.

\section{Statistic analysis:}

Statistical analysis was performed out with STATA 15.0. Qualitative variables were presented with their absolute and relative frequency distribution. Quantitative variables were summarized with median and interquartile range (IQR). Statystical analysis between qualitative variables with seronegativity at 4-8 weeks was evaluated using chi-square test or Fisher's exact test. Overall agreement between the three tests was studied by calculating kappa index together with its $95 \%$ confidence interval. A significance value of $5 \%$ was accepted for all tests. Data processing and analysis was carried out using statistical package STATA v.15.0.

\section{Results}

Amongst all consecutive patients who attended the Pediatric Emergency Department of both hospitals, 144 were selected. Of these 144 initial patients, the following were excluded: 12 for presenting a serology extraction outside the period of 4-8 weeks after the diagnosis of the infection, 2 who were immunosuppressed (HIV, juvenile rheumatoid arthritis treated with rituximab), 19 due to lack of blood sample to perform the three serological techniques. Final sample size analyzed was 111 patients. Median age of study population was 88 months 
(IQR: 24-149). Regarding the place of birth, most of them (54 children; 48.6\%) were born outside Spain but within Europe, in Spain 43 children (38.7\%), in Latin America 3 children (2.7\%), the rest being unknown (11 children, 9.9\%). Origin of parents was from Spain in 49 cases (44.1\%), from Latin America in 31 (27.9\%) and from Africa in 11 (9,9\%), from other countries 14 (12.6\%) and 6 cases unknown (5.4\%). Regarding underlying previous personal past history, respiratory symptoms were the most frequent (15 children; $13.5 \%$ ), specially recurrent bronchitis (Table 1). 
Table 1

Baseline characteristics of patients.

\begin{tabular}{|c|c|}
\hline \multicolumn{2}{|l|}{ Baseline characteristics of patients. } \\
\hline Gender & $\mathrm{n}(\%)$ \\
\hline Male & $53(47,7)$ \\
\hline Female & $58(52,2)$ \\
\hline Age (months) * & $88(24-149)$ \\
\hline$<2$ years old & $26(23,4)$ \\
\hline 2-10 years old & $45(40,5)$ \\
\hline$>10$ years old & $40(36,0)$ \\
\hline \multicolumn{2}{|l|}{ Personal history } \\
\hline Recurrent bronchitis / Asthma & $13(11,7)$ \\
\hline Bronchiolitis & $1(0,9)$ \\
\hline Pneumonia & $4(3,6)$ \\
\hline Prematurity & $4(3,6)$ \\
\hline Hypoxic-ischemic encephalopathy & $1(0,9)$ \\
\hline Autism & $1(0,9)$ \\
\hline Personality disorder & $1(0,9)$ \\
\hline Attention Deficit Hyperactivity Disorder & $1(0,9)$ \\
\hline Infant hemolytic anemia & $1(0,9)$ \\
\hline Celiac disease & $1(0,9)$ \\
\hline Others & $3(2,7)$ \\
\hline \multicolumn{2}{|l|}{ Place of birth } \\
\hline Unknown & $11(10,0)$ \\
\hline Known & $100(90,0)$ \\
\hline Europe (not Spain) & $54(48,6)$ \\
\hline Spain & $43(38,7)$ \\
\hline Central and South America & $3(2,7)$ \\
\hline Unknown & $11(9,9)$ \\
\hline \multicolumn{2}{|l|}{ Parents' origin } \\
\hline Spain & $49(44,1)$ \\
\hline Central and South America & $31(27,9)$ \\
\hline Africa & $11(9,9)$ \\
\hline Asia & $6(5,4)$ \\
\hline Europe (not Spain) & $5(4,5)$ \\
\hline Other origin & $3(2,7)$ \\
\hline Unknown & $6(5,4)$ \\
\hline
\end{tabular}


Most patients (94 children; 84.7\%) were attended for clinical suspicion, the rest were initially asymptomatic evaluated as close contacts. About symptoms, feverish symptoms prevailed in 78 patients (70\%) (fever 55\% and low-grade fever $15 \%$ ) followed by respiratory symptoms (61 patients; 55\%). To a lesser extent, 42 children (37.8\%) had gastrointestinal symptoms and 41 children (36.9\%) had neurological symptoms. Only 8 patients (7.2\%) reported skin involvement. Hyporexia was reported in 14 children (12.6\%), odynophagia in 8 (7.2\%), and irritability in 4 children (3.6\%). Only 9 cases (8.1\%) presented other symptoms, such as angioedema in the lower lip, apnea pause, vasovagal syncope, otalgia, eye pain and coincident UTI (Table 2). Of all children included, 8 patients (7.2\%) required hospital admission due to COVID-19 [median admission 2 days (IQR: 2-4)]. Most required only hospital monitoring due to their young age, one case needed oxygen therapy in nasal canula, and two cases intravenous fluid therapy due to low oral intake. None of them required corticosteroids, other immunomodulators or antiviral therapy. 
Table 2

Patient symptoms

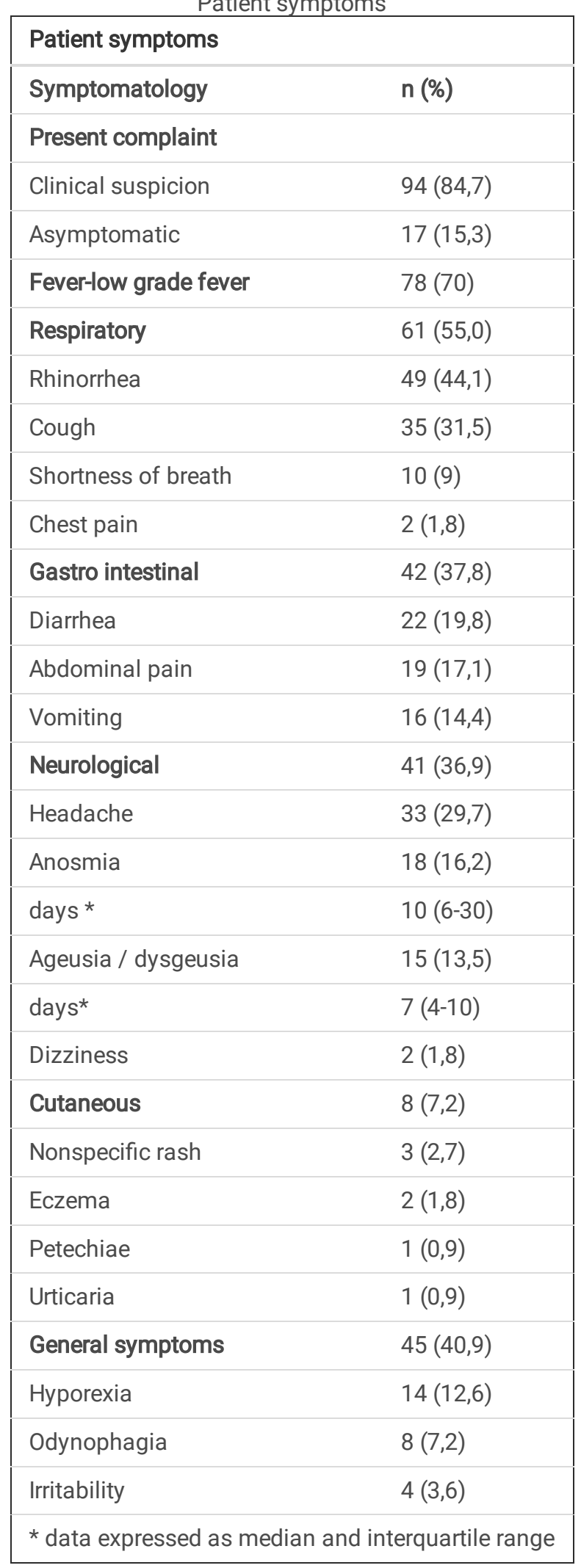

The patient was the index case within their families in 53 cases (47.7\%). In the rest of 58 cases (53.3\%), the index case patient was mostly within the family (96.4\%). Most of children (88 cases; $79.2 \%$ ) had household contacts with consistent COVID-19 symptoms and 81 (72.9\%) were positive confirmed by RT-PCR test. There was no confirmation of infection among household contacts in 29 cases (26.1\%).

Regarding serology, Abbott's test directed to the detection of IgG-N was negative in 25 (22.5\%) cases, compared to 22 (19.8\%) using the Siemens test directed to the detection of IgG-S and IgM-S and 20 (18\%) using Binding Site test that detects anti-RBD IgG / IgA / IgM 
antibodies. The median time of obtaining blood samples for serology from the diagnosis of positive RT-PCR was 37 days (IQR: $33-44)$. Global agreement between the three techniques measured by the kappa index was high (kappa: 0.89; 95\% Cl: 0.76-0.95), presenting an absolute agreement of $94.5 \%$. The three techniques were coincident in a positive result in $77.5 \%$ of cases and in a negative result in $17.1 \%$. When comparing tests two by two result was as follows: SARS-CoV-2 IgG II, Abbott with COV2T, Siemens (kappa: 0,92; IC 95\%:0,780,97), SARS-CoV-2 IgG II, Abbott with Human IgG/IgA/IgM anti-SARS-CoV-2 ELISA by The Binding Site Group (kappa:0,86; IC 95\%: 0,690,94), and COV2T, Siemens with Human IgG/IgA/IgM anti-SARS-CoV-2 ELISA by The Binding Site Group (kappa: 0,89; IC 95\%: 0,72-0,95).

The number of patients with seronegative results 4-8 weeks after the microbiological diagnosis by RT-PCR was 19 (17.1\% [95\% Cl: 10.625.4]). Table 3 shows the relationship of the different clinical and epidemiological variables with serologic status. Factors statistically significant associated with presenting a lower proportion of seropositivity were age between $2-10$ years (16 cases; $35.5 \%$, $95 \% \mathrm{Cl} 21.6-$ 49.5) and not confirmed disease in household contacts ( 15 cases, $51.7 \%, 95 \% \mathrm{Cl} 33.5-69.9)$. 
Table 3

Factors associated with seronegativity

\begin{tabular}{|c|c|c|}
\hline & Negative serology $n(\%)$ & $P$ \\
\hline Personal history of previous pathology & & 0,038 \\
\hline None & $10(12,5)$ & \\
\hline Yes & $9(29,0)$ & \\
\hline Age & & $<0,001$ \\
\hline $2-10$ years old & $16(35,6)$ & \\
\hline Other age & $3(4,5)$ & \\
\hline Gender & & 0,331 \\
\hline Male & $11(20,8)$ & \\
\hline Female & $8(13,8)$ & \\
\hline Parents origin & & 0,124 \\
\hline Spain & $11(22,4)$ & \\
\hline Central and South America & $2(6,5)$ & \\
\hline Others & $2(10,5)$ & \\
\hline Close contacts study & & 0,950 \\
\hline None & $16(17,0)$ & \\
\hline Yes & $3(17,6)$ & \\
\hline Asymptomatic patient & & 0,860 \\
\hline None & $17(17,3)$ & \\
\hline Yes & $2(15,4)$ & \\
\hline Fever-Low grade fever & & 0,846 \\
\hline None & $6(18,2)$ & \\
\hline Yes & $13(16,7)$ & \\
\hline Respiratory symptoms & & 0,195 \\
\hline None & $6(12)$ & \\
\hline Yes & $13(21,3)$ & \\
\hline Gastro intestinal symptoms & & 0,255 \\
\hline None & $14(20,3)$ & \\
\hline Yes & $5(11,9)$ & \\
\hline Neurologycal symptoms & & 0,036 \\
\hline None & $16(22,9)$ & \\
\hline Yes & $3(7,3)$ & \\
\hline Cutaneous symptoms & & 0,539 \\
\hline None & $17(16,5)$ & \\
\hline Yes & $2(25,0)$ & \\
\hline General symptoms & & 0,155 \\
\hline
\end{tabular}




\begin{tabular}{|lll|}
\hline & Negative serology n(\%) & $P$ \\
\hline None & $14(21,5)$ & \\
\hline Yes & $5(11,1)$ & 0,182 \\
\hline Hospitalization & & \\
\hline None & $19(18,4)$ & \\
\hline Yes & $0(0,0)$ & \\
\hline Index case patient & & \\
\hline None & $3(5,4)$ & $<0,001$ \\
\hline Yes & $16(30,2)$ & \\
\hline CoVID-19 confirmation in household contacts & & \\
\hline None & $15(51,7)$ & \\
\hline At least one & $4(4,9)$ & \\
\hline
\end{tabular}

\section{Discussion}

Our study corroborate the mild disease in children during the second wave of the SARS-COV-2 pandemic in Spain $2,23,24$. In keeping with other paediatric series, the most commonly reported symptoms were fever followed by mild respiratory syndrome, headache and gastrointestinal disease ${ }^{6}$.

In a Spanish Paediatric Association review of COVID-19 manifestations in childhood, 18 studies were selected, mainly from Europe (52\%) and mostly in patients admitted to hospital. Some differences were found compared to our group of patients. Fever followed by mild respiratory and gastrointestinal symptoms were the ones most commonly reported ${ }^{25}$. General as well as neurological symptoms were also reported, mainly fatigue, and headache, similar to our study. Dyspnoea was more common amongst the European group, and abdominal pain was the most frequent gastrointestinal manifestation ${ }^{25}$. Few children in our study required hospitalisation or specific treatment. During the second wave of the pandemic a nasopharyngeal sample RT-PCR was performed per protocol to every child with symptoms consistent with COVID-19. This might explain why in our series a mild course of the disease was more common compared to the first wave studies ${ }^{24}$. As previously reported in the literature, the index case at home was a child in less than $50 \%$ of cases, suggesting that adults are the main source of infection?

In our study a large proportion of children were living with adults with symptomatic COVID-19 and adults with confirmed disease by RTPCR.

The proportion of non seroconverters is high in our study with either the 3 serological techniques and seems to be higher than the figures reported in adulthood ${ }^{11}$.

Given the fact that the infection in childhood is frequently asymptomatic or paucisymptomatic it is possible that the proportion of individuals in whom no antibodies are detected is higher amongst the paediatric population as compared to the adult patients.

A progressive decay of antibodies titers is observed both in children and adults in the following months after the infection. The levels of antibodies vary alongside, anti-spike ones may be found earlier than anti nucleoproteins and the latter can also disappear faster ${ }^{26}$. However, it is possible that despite the absence of $\mathrm{IgG}$ antibodies against $\mathrm{S}$ protein and nucleoprotein, other neutralising antibodies might be produced. These ones may last longer and be responsible for a long-lasting protection against the disease. In adulthood this protection has been reported up to 15 months ${ }^{18}$.

Information about the length of antibodies titers against different SARS-CoV-2 antigens is scarce in childhood ${ }^{20}$ and little is known about their progress in time. A decrease of $\lg G$ antibodies titers is observed six months after the infection both in children and adults ${ }^{20}$. However neutralising antibodies might stay high in the following months specially in children aged 3 or less, even with higher levels than the ones encountered in older children and in adults ${ }^{20}$. In a recent Italian study a persistence of neutralising antibodies is observed after 7-8 months of infection ${ }^{20}$. While IgG antinucleoprotein and anti-spike decrease over time and even disappear in up to $54 \%$ of patients ${ }^{20}$. In 
adults there is evidence of a correlation between antibodies against RBD of spike protein with neutralising antibodies. Nevertheless, the kinetics of these two types of antibodies might be different. ${ }^{27}$

Both the presence of anti-spike and antinucleoprotein antibodies are associated with a lower risk of reinfection in the following 6 month ${ }^{28}$. The infection gives rise to an immune response in most cases however the protection against a reinfection is unclear. Immune response can be either humoral or celular and more studies are needed ${ }^{26}$.

It is possible that the variability in the kinetics of the different antibodies accounts for the slightly observed difference in sensitivity among the types of serologic tests used in our study. In any case, the proportion of non-seroconverter children is high and seemingly higher than the one reported in adults, although its significance in terms of protection remains to be elucidated.

In our series there is a statistically significant association between seronegativity and the age group 2-10 years, or being contact with a non-confirmed COVID-19 household. Although the significance of these findings is uncertain, it could be related to the paucisymptomatology in this age group or due to a less exposure to the virus outside the familiar group. More studies are needed to determine factors involving the lack of seroconversion.

In terms of serology, we found a high concordance in the 3 tests used. Detection of antibodies using ELISA Human $\operatorname{lgG} / \operatorname{lgA} / \operatorname{lgM}$ anti SARS-CoV-2 yielded a higher sensitivity than with Abbot and Siemens techniques although the number of patients was small and therefore comparisons are not possible. Concordance between the 3 techniques adds value to our results on high grade of seronegativity in childhood as compared to adults ${ }^{11}$.

This study has somes limitations. The number of patients included is relatively small although it is related to the number of patients consecutively identified during the study period. It is a prospective analysis that may have missed some retrospective data obtained in a clinical and epidemiological questionnaire. Therefore, memory bias of parents and children may be present. Data were collected via questionnaires in an outpatient facility and some of them were not obtained in the precise moment the patients attended the emergency room. In some cases, we do not have accurate information about some symptoms such as loss of smell. The external validity of our study is limited because it only includes patients attended in the Emergency Department and may not be representative of the general population. Although SARSCoV2 diagnosis was based on a single positive PCR, due to the high prevalence at the time of the study (second wave of the pandemic in Spain), its positive predictive value is very high, in addition all patients had symptoms or an epidemiological situation that had a high clinical suspicion of infection that supports the positive PCR result

However, our study has several strengths. On the one hand its prospective design, in the second wave of the pandemic in Spain with a selection according to pre-established criteria of consecutive patients with a RT- PCR confirmed diagnosis. And on the other hand, the serologic testing were performed at the same time lapse after the infection, and using different serologic testing, giving strength to our results.

In summary, our results offer additional data of the mild clinical picture in children, who usually are not the index case in the family. In addition, our series suggest that the proportion of children in whom seroconversion is not detected may be higher than in adults. More studies are needed to determine the factors involved in the humoral response and its significance in SARS-CoV- 2 infected children.

\section{Abbreviations}

RT-PCR: reverse transcriptase polymerase chain reaction

SARS-CoV-2: severe acute respiratory syndrome coronavirus 2

COVID-19: coronavirus disease - 19

IQR: interquartile range

MIS-C: Multisystem inflammatory syndrome in children

RBD: receptor -binding domain

HIV: Human immunodeficiency virus

ELISA: enzyme-linked immunosorbent assay 


\section{Declarations}

\section{Ethical approval and consent to participate}

Approval was granted by the Ethics Committee of Hospital Clínico San Carlos Madrid (C.I. 20/647-E_COVID) and the Viability Committee of Hospital de Getafe (CV20/66). This work was performed in accordance with the ethical standards as laid down in the 1964 Declaration of Helsinki and its later amendments. Informed consent was obtained from all individual participants included in the study.

\section{Consent for publication}

Not applicable.

\section{Avalailability of data and materials}

The datasets used and/or analysed during the current study are available from the corresponding author on reasonable request.

\section{Competing interests}

All authors certify that they have no affiliations with or involvement in any organization or entity with any financial interest or non-financial interest in the subject matter or materials discussed in this manuscript.

All authors certify that they have no affiliations with or involvement in any organization or entity with any financial interest or non-financial interest in the subject matter or materials discussed in this manuscript.

The authors declare that they have no competing interests. All authors certify that they have no affiliations with or involvement in any organization or entity with any financial interest or non-financial interest in the subject matter or materials discussed in this manuscript.

\section{Funding}

This work has been carried out with the help of the IdISSC (Hospital Clínico San Carlos Health Research Institute) research project, with file number: SUBV.COV.2020.JRA.

No pharmaceutical or industry support was required.

\section{Author's contribution}

ICC, JRA, ARL and ABP have contributed to the conception, design, acquisition, analysis and interpretation of data, and writing, review and editing of the manuscript. ABS, MIR, BJA, SGM, BSS, IGB, DMA, JIA, EBM and ADI have contributed to the acquisition of data and revised the manuscript. MEFF has contributed to the analysis and interpretation of data and revised the manuscript.

All authors have reviewed and approved the submission of the manuscript.

\section{Acknowledgements}

Not applicable. 


\section{References}

1. Lu X, Zhang L, Du H, Zhang J, Li Y, Qu J, et al. SARS-CoV-2 Infection in Children. N Engl J Med. 2020 Apr 23;382(17):1663-1665.

2. Molina MA, Ruiz JA, Bueno M, Lavisier B, López R, Martín J, et al. Impacto de la pandemia COVID-19 en urgencias: primeros hallazgos en un hospital de Madrid. Anales de Pediatría, 2020 Nov; 93 (5):313-322.

3. Mehta NS, Mytton OT, Mullins EWS, Fowler TA, Falconer CL, Murphy OB, et al. SARS-CoV-2 (COVID-19): What do we know about children? A systematic review. Clin Infect Dis. 2020;71(9):2469-79.

4. Munro APS, Faust SN. COVID-19 in children: current evidence and key questions. Curr Opin Infect Dis. 2020;33(6):540-7.

5. Whittaker E, Bamford A, Kenny J, Kaforou M, Jones CE, Shah P, et al. Clinical Characteristics of 58 Children With a Pediatric Inflammatory Multisystem Syndrome Temporally Associated With SARS-CoV-2. JAMA. 2020 Jul 21;324(3):259-269.

6. Laws RL, Chancey RJ, Rabold EM, Chu VT, Lewis NM, Fajans M, et al. Symptoms and Transmission of SARS-CoV-2 Among Children Utah and Wisconsin, March-May 2020. Pediatrics. 2021 Jan;147(1): e2020027268.

7. Bi Q, Wu Y, Mei S, Ye C, Zou X, Zhang Z, et al. Epidemiology and Transmission of COVID-19 in Shenzhen China: Analysis of 391 cases and 1,286 of their close contacts [Internet]. bioRxiv. 2020.

8. Instituto de Salud Carlos III. Informe n ${ }^{\circ} 4$ sobre los casos de COVID-19 confirmados en España [Internet]. 02 de marzo de 2020. https://www.isciii.es/QueHacemos/Servicios/VigilanciaSaludPublicaRENAVE/EnfermedadesTransmisibles/Paginas/InformesCOVID19.aspx

9. Pollan M, Perez-Gomez B, Pastor-Barriuso R, Oteo J, Hernán MA, Pérez-Olmeda M, et al. Prevalence of SARS-CoV-2 in Spain (ENECOVID): a nationwide, population-based seroepidemiological study. Lancet. 2020 Aug 22;396(10250):535-544.

10. Carrillo J, Izquierdo-Useros N, Ávila-Nieto C, Pradenas E, Clotet B, Blanco J. Humoral immune responses and neutralizing antibodies against SARS-CoV-2; implications in pathogenesis and protective immunity. Biochem Biophys Res Commun. 2021 Jan 29;538:187191.

11. Zhao J, Yuan Q, Wang H, Liu W, Liao X, Su Y, et al, Antibody responses to SARS-CoV-2 in patients of novel coronavirus disease 2019, 2020 Nov 19;71(16):2027-2034.

12. Clinical and immunological assessment of asymptomatic SARS-CoV-2 infections. Long QX, Tang XJ, Shi QL, Li Q, Deng HJ, Yuan J, Hu JL, Xu W, Zhang Y, Lv FJ, Su K, Zhang F, Gong J, Wu B, Liu XM, Li JJ, Qiu JF, Chen J, Huang AL Nat Med. 2020;26(8):1200. Epub 2020 Jun 18.

13. Hansen CB, Jarlhelt I, Pérez-Alós L, Hummelshøj Landsy L, Loftager M, et al. SARS-CoV-2 Antibody Responses Are Correlated to Disease Severity in COVID-19 Convalescent Individuals. J Immunol. 2021 Jan 1;206(1):109-117.

14. Juan Carlos de Carlos Vicente, María Slocker Barrio, Sylvia Belda Hofheinz, Iolanda Jordan García, Juan José Menéndez, Suso Julio Parrilla et al. Documento de manejo clinico del paciente pediátrico con infeccion por sarscov-2 en cuidados intensivos [Internet]. 2020. http://www.secip.com/wpcontent/uploads/2020/10/Protocolo_SECIP_v9_OCT2020.pdf

15. Coronavirus Infections in Children Including COVID-19: An Overview of the Epidemiology, Clinical Features, Diagnosis, Treatment and Prevention Options in Children. Petra Zimmermann and Nigel Curtis. Pediatr Infect Dis J. 2020 May; 39(5): 355- 368. Published online 2020 Mar 12.

16. Ibarrondo FJ, Rapid Decay of Anti-SARS-CoV-2 Antibodies in Persons with Mild Covid-19. N Engl J Med 2020; 383:1085-1087.

17. Pradenas E, Trinité B, Urrea V, Marfil S, Ávila-Nieto C, Rodríguez de la Concepción ML, et al. Stable neutralizing antibody levels 6 months after mild and severe COVID-19 episodes. Med (N Y). 2021 Mar 12;2(3):313-320.e4.

18. Pradenas E, Trinité B, Urrea V, Marfil S, Tarrés-Freixas F, Ortiz R, et al. Clinical course impacts early kinetics and long-term magnitude and amplitude of SARS-CoV-2 neutraliing antibodies beyond one year after infection.

19. A.K. Wheatley, J.A. Juno, J.J. Wang, K.J. Selva, A. Reynaldi, H.-X. Tan, W.S, et al. Evolution of immunity to SARS-CoV-2. medRxiv 2020.

20. Bonfante F, Costenaro P, Cantarutti A, Di Chiara C, Bortolami A, Petrara MR et al. Pediatrics 2021, e2021052173.

21. Estrategia de detección precoz, vigilancia y control de COVID-19. Actualizado 9 de julio de 2020. https://www.semg.es/images/2020/Coronavirus/20200709_COVID19_Estrategia_vigilancia_y_control_e_indicadores.pdf

22. Organización Mundial de la Salud. Protocolo de investigación de los primeros casos y sus contactos directos (FFX) de la enfermedad por Coronavirus 2019 (COVID-19). 2020 Feb 10. https://www.who.int/docs/default-source/coronaviruse/covid-19-master-ffxprotocol-v2-sp-web.pdf?sfvrsn=7ad940f_8.

23. De Ceano-Vivas M, Martín-Espín I, Del Rosal T, Bueno-Barriocanal M, Plata-Gallardo M, Ruiz-Domínguez JA, et al. SARS-CoV-2 infection in ambulatory and hospitalised Spanish children. Arch Dis Child. 2020 Aug;105(8):808-809. 
24. Tagarro A, Epalza C, Santos M, Sanz-Santaeufemia FJ, Otheo E, Moraleda C, Calvo C. Screening and Severity of Coronavirus Disease 2019 (COVID-19) in Children in Madrid, Spain, JAMA Pediatr. 2020 Apr 8:e201346.

25. Comité Grupo de Pediatría basada en la Evidencia de la AEP y AEPap. COVID-19 en Pediatría: valoración crítica de la evidencia (documento en revisión externa). $1^{\text {a }}$ edición 2021[consultado el 16/05/2021]. https://www.aeped.es/comite-pediatria-basada-enevidencia/documentos/covid-19-en-pediatria-valoracion-critica-evidencia.

26. Lumley SF, Wei J, O’Donnell D, Stoesser NE, Matthews PC, Howarth A, et al. The duration, dynamics and determinants of SARS-CoV-2 antibody responses in individual healthcare workers. Clin Infect Dis 2021 Aug 2;73(3):e699-e709.

27. Evolution of immune responses to SARS-CoV-2 in mild-moderate COVID-19. Adam K. Wheatley, Jennifer A. Juno, Jing J. Wang, Kevin J. Selva, Arnold Reynaldi, Hyon-Xhi Tan1 et al. NATURE COMMUNICATIONS (2021) 12:1162

28. Lumley SF, O'Donnell D, Stoesser NE, Matthews PC, Howarth A, Hatch SB, et al. Antibody status and incidence of SARS-CoV-2 infection in health care workers. N Engl J Med. 2021;384(6):533-40. 